\title{
The Thuggacins, Novel Antibacterial Macrolides from Sorangium cellulosum Acting against Selected Gram- positive Bacteria
}

\author{
Production, Antimicrobial Activity and Mechanism of Action
}

Herbert Irschik, Hans Reichenbach, Gerhard Höfle, Rolf Jansen

Received: August 16, 2007 / Accepted: November 28, 2007

(C) Japan Antibiotics Research Association

\begin{abstract}
In our screening program we found an activity against some Gram-positive bacteria, including mycobacteria in the culture supernatant of Sorangium cellulosum strain So ce895. The antibiotic responsible for this activity was isolated and named thuggacin. Initial studies towards the mechanism of action showed that thuggacin A inhibits a late step of the respiratory chain of some bacteria.
\end{abstract}

Keywords Sorangium cellulosum, antibiotics, macrolides, respiration, thuggacin

\section{Introduction}

In the last few years, we isolated many strains of the order myxobacteria from soil samples collected from all over the world. The screening program comprised tests for cytotoxic, antifungal and antibacterial activities accompanied by HPLC-diode array UV analysis (HPLCUV-DAD). The results showed that myxobacteria are a rich source of new secondary metabolites [1]. Sorangium cellulosum strain So ce895 showed an activity especially against some mycobacteria with a HPLC and UV spectrum not yet known to us. The active compounds were isolated

H. Irschik (Corresponding author), R. Jansen: Research Group Microbial Drugs

H. Reichenbach, G. Höfle: Helmholtz Zentrum für Infektionsforschung, Inhoffenstr. 7, D-38124 Braunschweig (former Gesellschaft für Biotechnologische Forschung (GBF)),

E-mail: herbert.irschik@helmholtz-hzi.de and the structures were elucidated [2] (Fig. 1).

This report gives some data on the production and the biological activities of thuggacins A, B and C. Thuggacin A acts on the respiration of some bacteria. Electron transport chains in microorganisms with their different enzyme complexes are described in [3]. NADH driven electron flow begins with the oxidation of $\mathrm{NADH}$ and the reduction of ubiquinone by NADHoxidase. Then in several bacteria, e.g. Micrococcus luteus and Mycobacterium phlei, electrons are transferred to cytochrome $\mathrm{c}$ by an enzyme complex containing cytochromes $\mathrm{bc}_{1}$. The last step is the reduction of oxygen by the cytochrome $\mathrm{c}$ oxidase (terminal oxidase), containing the cytochromes $\mathrm{aa}_{3}$. Other bacteria like Escherichia coli oxidize the ubiquinone by an ubiquinol oxidase. In most cases bacteria have more than one terminal oxidase with different cytochromes.

\section{Materials and Methods}

\section{Fermentation}

The producing strain was isolated from a soil sample in 1993.

The antibiotic was produced by fermentation. The medium consisted of soluble starch $0.6 \%$, yeast extract $0.2 \%, \mathrm{KNO}_{3} 0.04 \%, \mathrm{NH}_{4} \mathrm{Cl} 0.06 \%, \mathrm{CaCl}_{2} \cdot 2 \mathrm{H}_{2} \mathrm{O} \quad 0.1 \%$, $\mathrm{MgSO}_{4} \cdot 7 \mathrm{H}_{2} \mathrm{O}, 0.1 \%$, glucose $\cdot \mathrm{H}_{2} \mathrm{O} \quad 0.35 \%$, Na-Fe-EDTA $8.0 \mathrm{mg} /$ liter, and Amberlite adsorber resin XAD-16 1.0\%.

The $\mathrm{pH}$ was adjusted with $\mathrm{KOH}(20 \%)$ to 7.4 before autoclaving and was kept at 7.0 with $\mathrm{KOH}(5.0 \%)$.

The fermentation conditions were: inoculum, $2.0 \%(\mathrm{v} / \mathrm{v})$; 
temperature, $30^{\circ} \mathrm{C}$; stirring rate, $80 /$ minute; aeration, 0.05 liters/liter culture/minute until the $\mathrm{pO}_{2}$ decreased to $20 \%$, and was kept at this value by variation of the stirring rate.

\section{Isolation}

The XAD was separated from the culture and the antibiotic was isolated as described elsewhere [2].

\section{Biological Assays}

MIC values were determined according to [4]. Bacteria, initial cell concentration of $10^{5}$ cells $/ \mathrm{ml}$, were incubated overnight at $30^{\circ} \mathrm{C}$ in a medium containing peptone.

Macromolecular Synthesis

The synthesis of DNA, RNA and protein in Micrococcus luteus were measured as described in [4]. The precursors were $\left[{ }^{3} \mathrm{H}\right.$-methyl $]$ thymine $(53.2 \mathrm{Ci} / \mathrm{mmol}), 2-\left[{ }^{14} \mathrm{C}\right]$-uracil $(60 \mathrm{Ci} / \mathrm{mol})$ and $\mathrm{U}-\left[{ }^{14} \mathrm{C}\right]$-protein hydrolysate $(50 \mathrm{Ci} /$ gramatom C).

\section{Oxygen Consumption}

An overnight culture of Micrococcus luteus was diluted to an optical density $(623 \mathrm{~nm})$ of 0.5 in growth medium. Measurement of oxygen was performed at $30^{\circ} \mathrm{C}$ in a RE K1-1 N device from Biolytik, Bochum, Germany.

\section{Respiratory Chain Measurements}

A crude fraction of cytoplasmic membranes of Micrococcus luteus was isolated as follows.

Cells from an overnight culture were harvested by centrifugation and washed twice with $50 \mathrm{mM}$ phosphate buffer, $\mathrm{pH}$ 7.8. Then the cells were burst in a French pressure cell at $16,000 \mathrm{psi}$. The suspension was centrifuged at $15,000 \times g$ for 20 minutes and the supernatant at $160,000 \times g$ for 1.5 hours. The pellet was resuspended in phosphate buffer and frozen at $-80^{\circ} \mathrm{C}$. For measurements, it was thawed at room temperature. Cytoplasmic membranes of other microorganisms were isolated in the same way.

$\mathrm{NADH}$ oxidation and particular steps of the respiratory chain were measured as followed: NADH oxidase at $340 \mathrm{~nm}$ starting with $0.255 \mathrm{mM} \mathrm{NADH}, \mathrm{NADH}$ dehydrogenase at $578 \mathrm{~nm}$ starting with $0.255 \mathrm{mM} \mathrm{NADH}$ and $0.066 \mathrm{mM} 2,6-$ dichlorophenolindophenol and $2.0 \mathrm{mM} \mathrm{KCN}$, NADH: cytochrome c reductase at $546 \mathrm{~nm}$ with $0.255 \mathrm{mM} \mathrm{NADH}$ and $0.05 \mathrm{mM}$ horse heart cytochrome $\mathrm{c}$ and $2.0 \mathrm{mM} \mathrm{KCN}$, cytochrome c oxidase at $550 \mathrm{~nm}$ with $100 \mathrm{mM}$ reduced cytochrome $c[5,6]$. The protein concentration of the cytoplasmic membrane in these tests was $0.028 \mathrm{mg} / \mathrm{ml}$. The membranes were suspended in prewarmed $\left(30^{\circ} \mathrm{C}\right)$ airsaturated phosphate buffer. Electron acceptor, if necessary, and inhibitor were added and incubated for 2 minutes. Then the reaction was started with NADH and the absorbence was measured at $30^{\circ} \mathrm{C}$ during 10 minutes.

Cytochrome difference spectra were recorded in an AMINCO DW $2000 \mathrm{UV} /$ VIS spectrophotometer at $30^{\circ} \mathrm{C}$ according to [7]. Concentration of NADH: $1.4 \mathrm{mg} / \mathrm{ml}$, thuggacin A: $20 \mu \mathrm{g} / \mathrm{ml}, \quad \mathrm{KCN}: 240 \mu \mathrm{g} / \mathrm{ml}$, protein concentration of the membranes: $1.4 \mathrm{mg} / \mathrm{ml}$. Preincubation of membranes was as above. Then NADH was added to the sample cuvette, whereas the reference cuvette contained membranes only. For measurement of the baseline there were membranes in both cuvettes without addition of $\mathrm{NADH}$. When the reduction was at its maximum, the difference spectrum was recorded. In these tests the concentrations of the inhibitors thuggacin and $\mathrm{KCN}$ were higher than for measurement of enzyme reactions, because the concentration of the membranes was higher [7]. Beside this there was no experience with membranes from bacteria. So high concentrations were used.

\section{Results}

\section{Production of Thuggacin}

Fig. 2 shows that after a lag phase of 2 days the strain grew exponentially for 3 days, then growth slowed down. At day 7, the cells began to lump together. The production of thuggacin A did not begin unitil day 5 when exponential

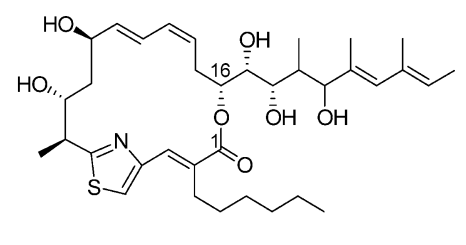

Thuggacin A

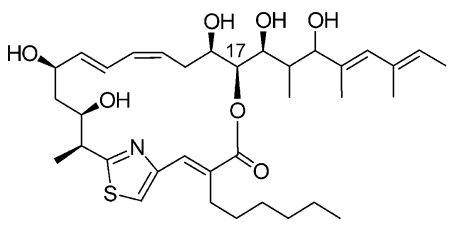

Thuggacin B

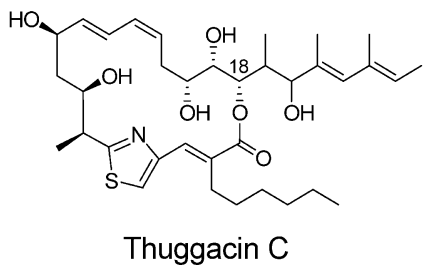

Fig. 1 Structures of thuggacins A, B and C. 


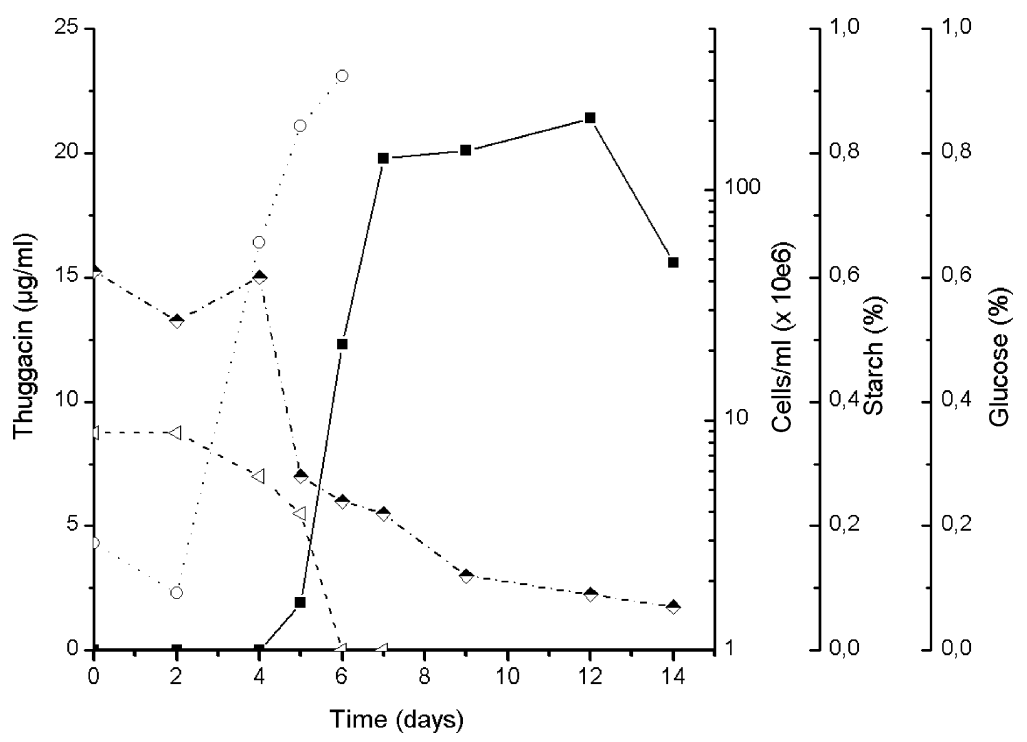

Fig. 2 Production of thuggacin A in a 10-liter fermentor.

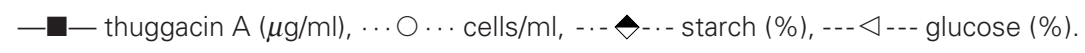

growth slowed down. It continued for two days and reached a maximum value of the antibiotic of $21 \mu \mathrm{g} / \mathrm{ml}$. After this the level remained constant for the next 5 days. The concentration of starch did not change during the first four days, but then the starch was quickly used up. Glucose, on the other hand, was used up by until day 6 .

\section{Biological Effect of Thuggacin}

Thuggacin inhibited the growth of some Gram-positive bacteria, especially of Micrococcus luteus and of species of the genera Corynebacterium and Mycobacterium. But great differences of the MIC values were observed within these groups. The activities of thuggacins $\mathrm{A}$ and $\mathrm{B}$ were rather similar, but thuggacin $\mathrm{C}$ was much less active. They were not active against yeasts and fungi. The mouse fibroblast cell line L929 was moderately sensitive to thuggacin A (Table 1).

The mode of action of thuggacin A was studied using Micrococcus luteus. The syntheses of DNA, RNA and protein, measured as incorporation of radioactive precursors, were stopped immediately after the addition of the antibiotic (Fig. 3).

Results from the measurement of the oxygen consumption of Micrococcus luteus under the influence of thuggacin are presented in Fig. 4. It shows that respiration was inhibited to $100 \%$ with $2.5 \mathrm{ng} / \mathrm{ml}$. The figure further gives the inhibition of NADH oxidation of cytoplasmic membranes of $M$. luteus. The maximum inhibition of $\mathrm{NADH}$ oxidation reached $90 \%$ at $10 \mathrm{ng} / \mathrm{ml}$ thuggacin A. As a control, with $60 \mu \mathrm{g} / \mathrm{ml} \mathrm{KCN}$, there also was a maximal
Table 1 MIC values of thuggacin A

\begin{tabular}{lc}
\hline \multicolumn{1}{c}{ Test organism } & MIC $(\mu \mathrm{g} / \mathrm{ml})$ \\
\hline Staphylococcus aureus GBF & $>20$ \\
Bacillus subtilis GBF & 5 \\
Corynebacterium mediolanum GBF & 5 \\
Corynebacterium glutamicum DSM20300 & 0.006 \\
Nocardia corallina GBF & 0.006 \\
Micrococcus luteus GBF & 0.003 \\
Mycobacterium phlei GBF & 0.03 \\
Mycobacterium chitae DSM43238 & 0.6 \\
Mycobacterium smegmatis DSM43856 & 40 \\
Mycobacterium diernhoferii DSM43218 & 20 \\
Escherichia coli DSM5698 & $>20$ \\
Saccharomyces cerevisiae GBF & $>80$ \\
\hline & $\mathrm{IC}_{50}(\mu \mathrm{g} / \mathrm{ml})$ \\
\hline Mouse fibroblast cells L929 & 4 \\
\hline
\end{tabular}

inhibition of $90 \%$. Fig. 4 also shows that the cytochrome oxidase, using reduced cytochrome c, was inhibited comparably to the inhibition of NADH oxidation. The system NADH-cytochrome c oxidoreductase was not influenced until at least $1000 \mathrm{ng} / \mathrm{ml}$ (data not shown). Fig. 5 shows difference spectra of the cytochromes in crude membranes of $M$. luteus reduced by NADH versus air oxidized membranes, with or without inhibitors. Thuggacin A gives a partial inhibition of the reduction of cytochrome 

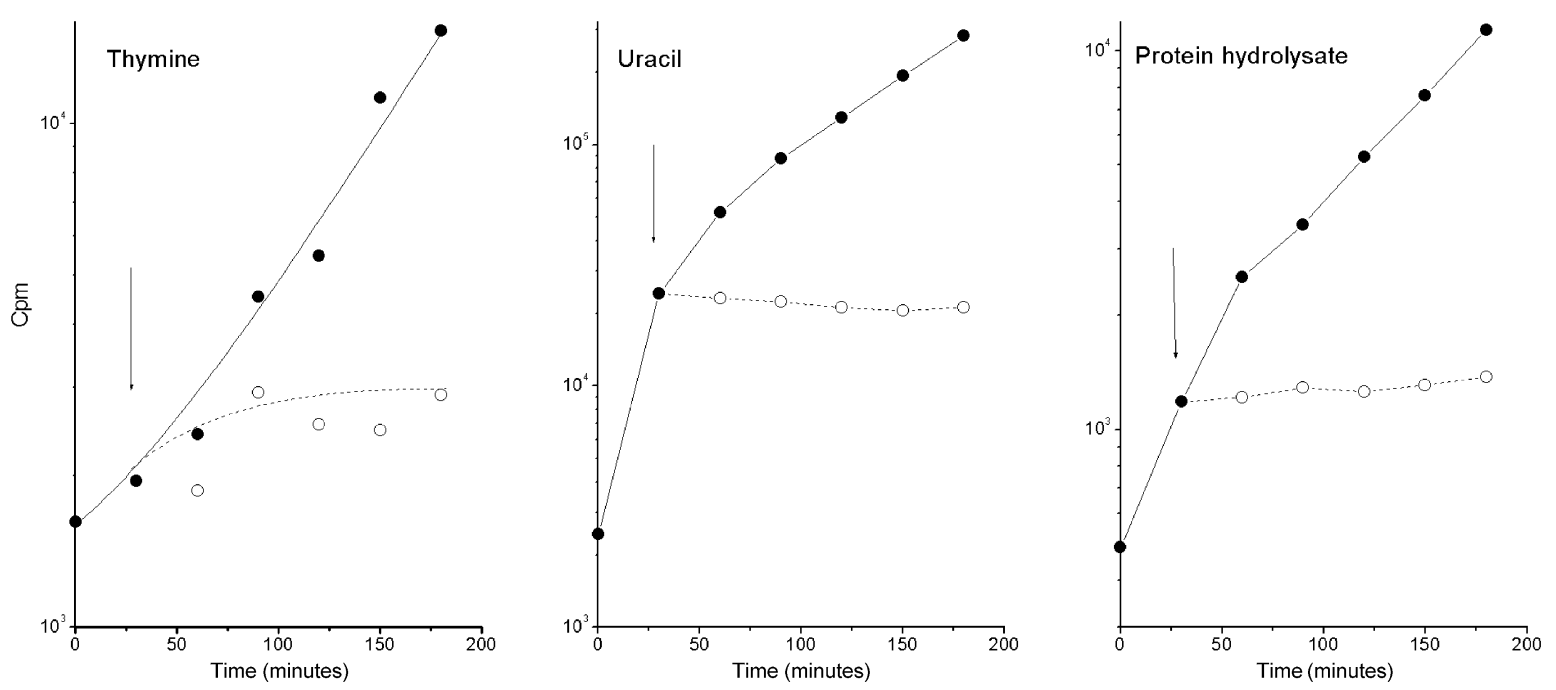

Fig. 3 Synthesis of some macromolecules in cells of M. luteus.

Incorporation of precursors of DNA, RNA and Protein was measured arrow shows time of addition of the antibiotic. $\bullet$; Control, O; 20 ng thuggacin $\mathrm{A} / \mathrm{ml}$.

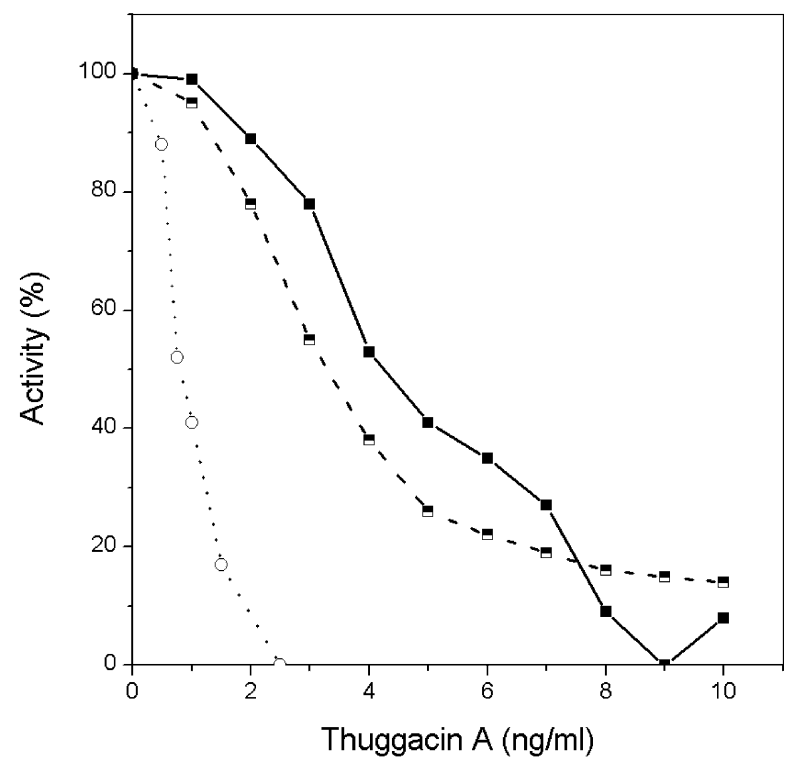

Fig. 4 Effects of thuggacin $A$ on the oxygen consumption in M. luteus, and NADH oxidase and cytochrome c oxidase in cytoplasmic membranes of $M$. luteus.

$100 \%$ activity of $\mathrm{NADH}$ oxidase was $0.0149 \mathrm{mM} \mathrm{NADH}$ minute $^{-1}$ and of cytochrome c oxidase $0.117 \mu \mathrm{M}$ cytochrome $\mathrm{c}$ minute $^{-1}$. .... Oxygen demand of $M$. luteus cells, -- --$\mathrm{NADH}$ oxidation in $\mathrm{CM}$ from $M$. luteus, - - cytochrome $\mathrm{C}$ oxidase in $\mathrm{CM}$ from M. luteus.

a $(600.9 \mathrm{~nm})$, cytochrome b $(560.3 \mathrm{~nm})$ and cytochrome c $(551.7 \mathrm{~nm})$. A similar, but not identical, result was obtained with $\mathrm{KCN}$, as the reduction of cytochrome b was slightly less and that of cytochrome c slightly more inhibited than with thuggacin.

Cytoplasmic membranes (crude fractions) were also isolated from Mycobacterium phlei, Corynebacterium glutamicum, Escherichia coli, Staphylococcus aureus and Bacillus subtilis.

Only the respiratory chains of $M$. phlei (NADH oxidase, $\mathrm{IC}_{50}: 5.0 \mathrm{ng} / \mathrm{ml}$ ) and C. glutamicum (NADH oxidase, $\mathrm{IC}_{50}$ : $15 \mathrm{ng} / \mathrm{ml}$ ) showed similar sensitivities for thuggacin A as that of $M$. luteus.

\section{Discussion}

The thuggacins constitute a novel group of macrolide antibiotics (Fig. 1). They are produced by some strains of the myxobacterium Sorangium cellulosum. In strain So ce895 they were produced in the late log phase of growth and excreted into the medium up to values of about $20 \mu \mathrm{g} / \mathrm{ml}$ (Fig. 2).

Thuggacin proved to be active against some Grampositive bacteria, all of them belonging to the Actinomycetales (Table 1).

The syntheses of three important macromolecules (DNA, RNA and protein) were inhibited immediately after the addition of the antibiotic (Fig. 3). Further measurements indicated that the energy supply of whole cells was interrupted by inhibition of the oxygen consumption (Fig. 4). Measurements of the activity of the respiratory chain in cytoplasmic membranes corroborated this result. Both, oxidation of NADH and of cytochrome c, were inhibited (Fig. 4), but not the reduction of added oxidized 


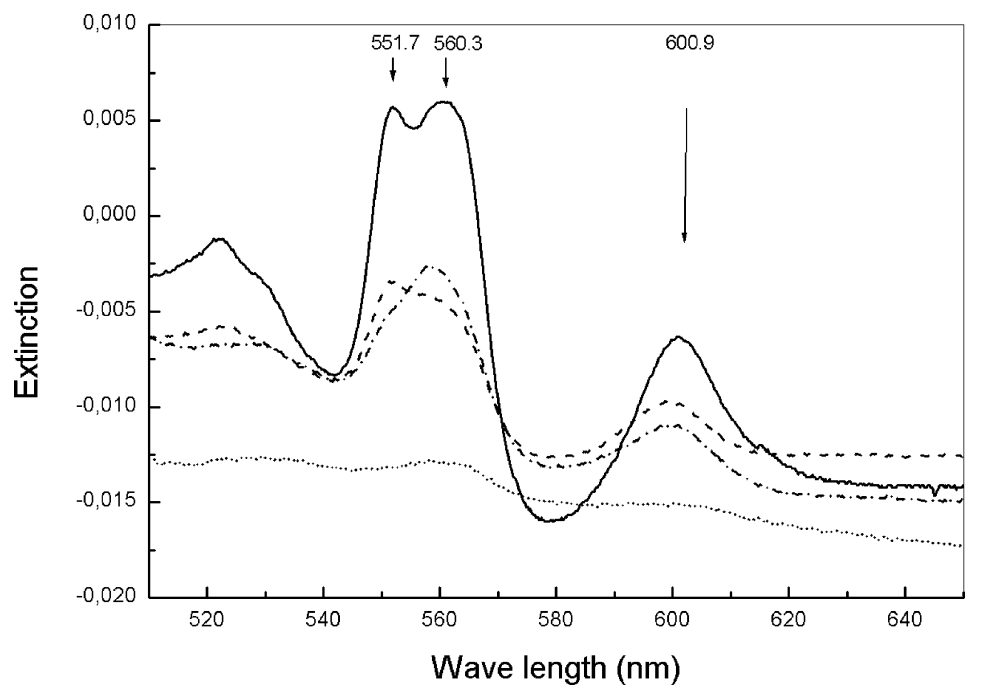

Fig. 5 Influence of thuggacin A on the reduction of cytochromes by NADH in membranes of M. luteus suspended in airsaturated buffer.

........; Baseline without NADH and inhibitor, -...-; with NADH and KCN, ----; with NADH and thuggacin, _-; with NADH alone.

cytochrome c by NADH. There remains unexplained difference between the total inhibition observed in whole cells and a non-inhibitable rest activity in membrane fractions. However, as described $[8,9]$, there are alternative electron pathways in Micrococcus luteus and other bacteria resulting in an incomplete inhibition by KCN. Fig. 5 gives the difference spectra with membranes of $M$. luteus. Both $\mathrm{KCN}$ and thuggacin show a similar inhibition of the reduction of cytochrome a.

On the other hand, inhibition at 551.7 (cytochrome c) and $560.3 \mathrm{~nm}$ (cytochrome b) differs slightly.

The data presented in Figs. 4 and 5 indicate that one of the late steps of the respiratory chain is the target of thuggacin. The small deviations between $\mathrm{KCN}$ and thuggacin in the inhibition of the cytochromes may be due to different binding sites. But the inhibition of the reduction of all the cytochromes is not yet completely understood.

Similar results as with $M$. luteus were obtained with membranes of Mycobacterium phlei and Corynebacterium glutamicum. The latter organism is of special interest because the molecular composition of the components of the respiratory chain is under investigation [9].

The tolerance of Staphylococcus aureus, Bacillus subtilis and Escherichia coli to thuggacin corresponds to the insensitivity of the NADH oxidation in cytoplasmic membranes of these organisms.

So thuggacins are an additional novel group of antibiotics from myxobacteria that acts on the electron transport chain $[10,11]$, but it seems to be selectively restricted to a few organisms. On the other hand, it may be of a certain interest because of its activity against Mycobacterium tuberculosis strain H37RV showing a MIC value of $8.0 \mu \mathrm{g} / \mathrm{ml}$ [RüschGerdes, S., Forschungszentrum Borstel, Germany, personal communication].

Acknowledgement We thank J. Lorenz and K. Schober for their skilful assistance, A. Roß and his coworkers for their contribution in fermentation, and B. Kunze for measuring the cytochrome difference spectra.

\section{References}

1. Reichenbach H, Höfle G. Myxobacteria as Producers of Secondary Metabolites. In Drug Discovery from Nature. Eds. S. Grabley, R. Thiericke, pp. 149-179, Springer, Berlin (1999)

2. Steinmetz H, Irschik H, Kunze B, Reichenbach H, Höfle G, Jansen R. Thuggacins - macrolide antibiotics active against Mycobacterium tuberculosis-isolation from Myxobacteria, structure elucidation, conformation analysis and biosynthesis. Chemistry-A European Journal 13: 5822-5832 (2007)

3. Anruka Y. Bacterial electron transport chains. Ann Rev Biochem 57: 101-132 (1988)

4. Irschik H, Augustiniak H, Gerth K, Höfle G, Reichenbach $H$. The ripostatins, novel inhibitors of eubacterial RNA polymerase isolated from Myxobacteria. J Antibiot 48: 787-792 (1995)

5. Irschik H, Oelze J. The effect of transfer from low to high light intensity on electron transport in Rhodospirillum rubrum. Arch Microbiol 109: 307-313 (1976)

6. Thierbach G, Reichenbach H. The effect of the new 
antibiotic myxothiazol on the respiration of Paracoccus denitrificans. Arch Microbiol 134: 104-107 (1983)

7. Kunze B, Jansen R, Höfle G, Reichenbach H. Ajudazols, new inhibitors of the mitochondrial electron transport from Chondromyces crocatus. J Antibiot 57: 151-155 (2004)

8. Artzatbanov V, Ostrovsky DN. The distribution of electron flow in the branched respiratory chain of Micrococcus luteus. Biochem J 266: 481-486 (1990)

9. Niebisch A, Bott M. Molecular analysis of the cytochrome $\mathrm{bc}_{1}-\mathrm{aa}_{3}$ branch of the Corynebacterium glutamicum respiratory chain containing an unusual diheme cytochrome $\mathrm{c}_{1}$. Arch Microbiol 175: 282-294 (2001)

10. Kunze B, Kemmer T, Höfle G Reichenbach H. Stigmatellin, a new antibiotic from Stigmatella aurantiaca (myxobacterales). J Antibiot 37: 454-461 (1984)

11. Kunze B, Höfle G, Reichenbach H. The aurachins, new quinolone antibiotics from myxobacteria: production, physico-chemical and biological properties. J Antibiot 40: 258-265 (1987) 